\title{
Patrimonio cultural, museos y visitantes en la ciudad de Cuenca
}

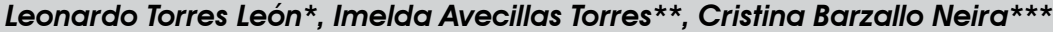 \\ $y$ Viviana Lliguin Balarezo****
}

\begin{abstract}
RESUMEN
El PRESENTE TRABAJO CONSTITUYE UNA DE LAS POCAS INVESTIGACIONES REALIZADAS SOBRE LOS MUSEOS DE LA CIUDAD de Cuenca, PeSe a SER instituciones que PReServan bienes Patrimoniales y son atractivos turísticos. Por ELLO, SE HA EMPRENDIDO UN PROGRAMA DE INVESTIGACIÓN QUE INICIA CON EL ESTUDIO DE LA PERCEPCIÓN DE LOS VISITANTES LOCALES, NACIONALES Y EXTRANJEROS EN SEIS MUSEOS DE LA CIUDAD DE CUeNCA. LAS PERCEPCIONES EXPRESADAS MEDIANTE COMENTARIOS ESCRITOS ESPONTÁNEAMENTE POR LOS VISITANTES ECUATORIANOS Y EXTRANJEROS (DE 91 NACIONALIDADES) EN EL LIBRO DE VISITA DE LOS MUSEOS, DURANTE EL AÑo 2016, CONSTITUYEN EL INSUMO FUNDAMENTAL DE INFORMACIÓN. DESDE UNA PERSPECTIVA CUALITATIVA, RECURRIENDO AL ANÁLISIS DE CONTENIDOS, SE EXAMINAN LAS IMPRESIONES CONSIGNADAS POR LOS VISITANTES. EL ESTUDIO MUESTRA QUE EL PATRIMONIO ES PERCIBIDO COMO HERENCIA, SE ASOCIA CON MEMORIA Y ANTE TODO SE VALORA SU CONSERVACIÓN EN LA MEDIDA QUE GARANTIZA LA CONTINUIDAd de LA MUESTRA y CON Ella LA POSIBILIDAd de GUARDAR SU CONTENIDO PARA LA POSTERIDAD. SE ADVIERTE UNA TENDENCIA ROMÁNTICA QUE SUBYACE EN LOS COMENTARIOS: EL MUSEO ESPACIO DONDE EL PASADO A TRAVÉS DE LA MUESTRA PERDURA DE FORMA INMUTABLE.

Palabras Clave: Patrimonio - museos - visitantes - turismo - Cuenca
\end{abstract}

\section{Cultural Heritage, Museums and Visitors in Cuenca}

\section{Abstract}

THE PRESENT WORK IS ONE OF THE FEW RESEARCH INVESTIGATIONS INTO THE MUSEUMS OF THE CITY OF CUENCA, DESPITE THE FACT THAT THESE ARE INSTITUTIONS THAT PRESERVE HERITAGE ASSETS AND ARE ALSO TOURIST ATTRACTIONS. FOR THIS REASON, A RESEARCH PROGRAM WAS STARTED TO STUDY THE PERCEPTIONS THAT LOCAL, NATIONAL AND FOREIGN Visitors have about the six museums in Cuenca. The perceptions expressed in Spontaneously Written COMMENTS by ECUAdorian AND FOREIGN Visitors (91 NATIONALITIES) IN THE Visitors' logs AT THE MUSEUMS DURING THE YEAR 2016 CONSTITUTE VITAL INFORMATIONAL INPUT. USING CONTENT ANALYSIS, IMPRESSIONS RECORDED BY VISITORS WERE EXAMINED FROM A QUALITATIVE PERSPECTIVE. THE STUDY SHOWS THAT HERITAGE IS PERCEIVED AS AN INHERITANCE, IS ASSOCIATED WITH MEMORY, AND ABOVE ALL THAT ITS CONSERVATION IS VALUED TO THE EXTENT THAT THE CONTINUITY OF THE EXHIBIT IS GUARANTEED, ALONG WITH THE POSSIBILITY TO SAVE ITS CONTENTS FOR POSTERITy. THERE IS A ROMANTIC TREND THAT UNDERLIES THE COMMENTS: THAT THE MUSEUM SPACE IS WHERE THE PAST REMAINS IMMUTABLE, THROUGH ITS EXHIBITION.

Keywords: Heritage - MUSEUMS - Visitors - TOURISM - CuenCA.

* Profesor Principal a Tiempo Completo de la Universidad de Cuenca, Facultad de Ciencias de la Hospitalidad. Máster en Integración Regional, por la Universidad de Cuenca y la Facultad Latinoamericana de Ciencias Sociales, FLACSO. Correo: leonardo.torres@ucuenca.edu.ec.

** Profesora Auxiliar a Tiempo Completo de la Universidad de Cuenca, Facultad de Ciencias de la Hospitalidad. Máster en Planificación Turística, por la Universidad del Azuay. Correo: imelda.avecillas@ucuenca.edu.ec.

*** Profesora Ocasional a Tiempo Completo de la Universidad de Cuenca, Facultad de Ciencias de la Hospitalidad. Máster en Planificación Turística, por la Universidad del Azuay. Correo: cristina.barzallon@ucuenca.edu.ec.

**** Estudiante de la Facultad de Ciencias de la Hospitalidad, Carrera de Turismo. Ayudante de Investigación. Correo: viviana.1liguinb@ucuenca.ec. 


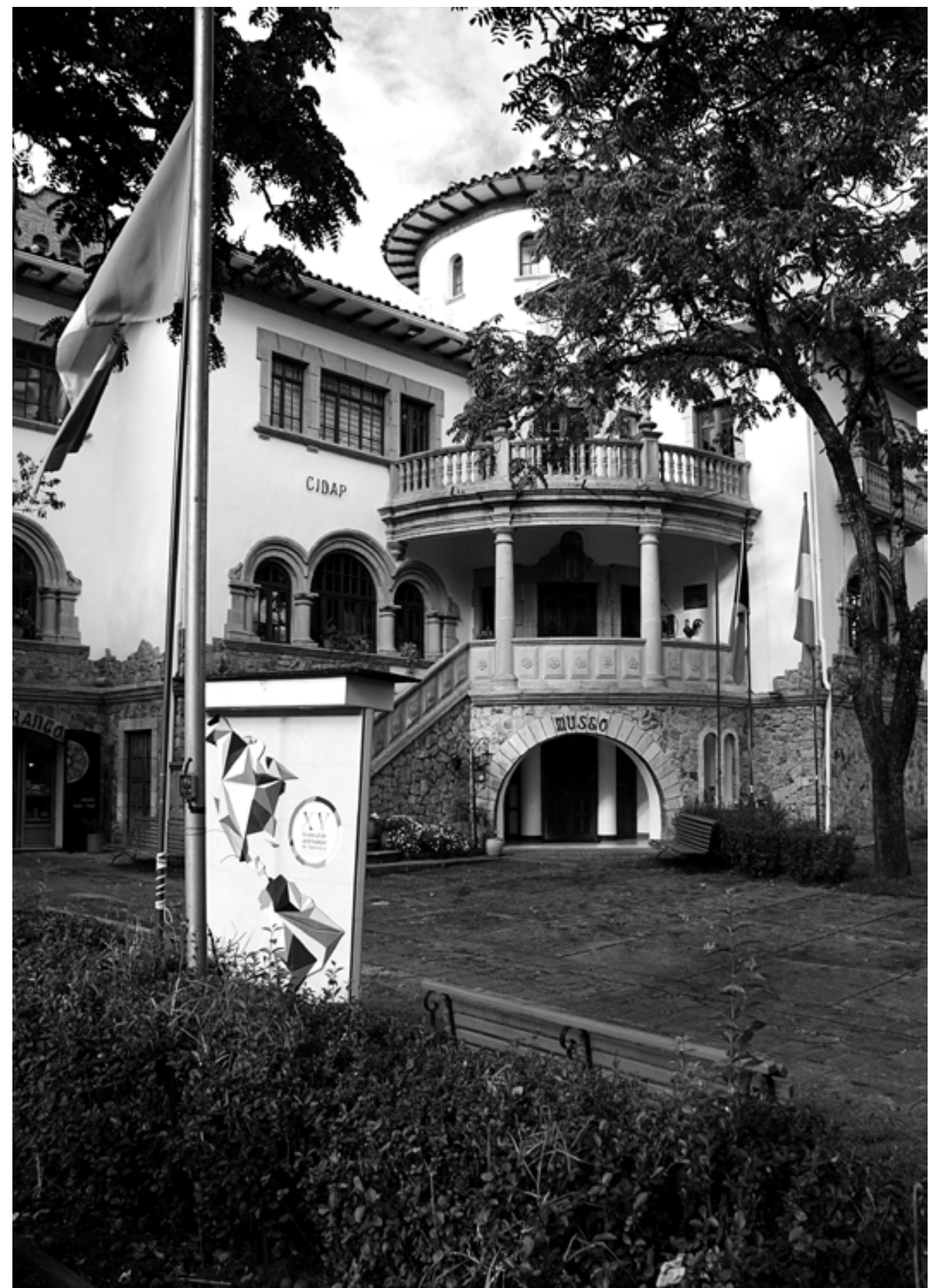

Museo Interamericano de Artes Populares. Foto: Juliana Torres Carrasco. 


\section{Introducción}

$\mathrm{E}$ 1 presente estudio es producto del proyecto de investigación: "El turismo cultural y los museos en el contexto de la ciudad patrimonial de Cuenca", el cual analiza en el área de intersección de los campos del turismo cultural, los museos y el patrimonio en el Departamento de Investigación de la Facultad de Ciencias de la Hospitalidad de la Universidad de Cuenca, desarrollado entre septiembre de $2016^{1}$ y febrero de 2018.

Los museos seleccionados para el desarrollo de este artículo fueron los que registraban el número de visitantes y contaban con un libro de visitas para recoger las impresiones del público local y extranjero. El enfoque metodológico de la investigación fue cualitativo con base en el análisis de los comentarios de los visitantes. Los criterios recopilados de los libros de visita, tuvieron como insumo 783 comentarios de los que se seleccionaron 590 y se utilizaron 147 referentes a la percepción del patrimonio cultural. Adicionalmente, se integró la información obtenida mediante entrevistas a directores de museos y guías de turismo; y, técnicas lógicosemánticas para establecer categorías y contenidos no explícitos que se encuentran en los comentarios de los visitantes (Colle, 2011: 7). La categoría principal fue la de patrimonio y en relación a ésta, las de historia, memoria, preservación y gestión.

Los seis museos analizados fueron: Museo Municipal de Arte Moderno (MMAM), Museo de las Culturas Aborígenes, Museo de las Conceptas, Museo Historia de la Medicina Guillermo Aguilar M., Reserva y Museo de las Artes Populares (CIDAP), y Museo Magia del Sombrero. Estos fueron seleccionados por las características de su muestra, y para apreciar la percepción del patrimonio de la ciudad de Cuenca, pues en ellos se pueden admirar exposiciones de arte moderno, arqueología precolombina, la religiosidad en la Colonia, la artesanía en general y en especial la del sombrero de paja toquilla - patrimonio inmaterial de la humanidad- y la evolución de la medicina en una ciudad que contó con la segunda facultad del área en el Ecuador. Adicionalmente, estos museos cuentan con un libro de visita y el registro de sus visitantes.

De acuerdo a las temáticas señaladas y en orden cronológico, es decir por el año de su fundación, detallamos a continuación los museos comprendidos en este estudio:

El Museo Municipal de Arte Moderno - MMAM (1981), pertenece a la Municipalidad de Cuenca. La edificación data de 1876 (Ilustre Municipalidad de Cuenca, Junta de Andalucía y Embajada de España, 2007: 115) y ha tenido múltiples usos desde su construcción. En 1978, la Municipalidad de Cuenca inició el proyecto de restauración del edificio para su uso como museo, cuya apertura se dio en 1981. El museo cuenta con cuatro salas y en ellas se realizan exposiciones de artistas nacionales y extranjeros, que muestran las tendencias de la plástica actual (Ilustre Municipalidad de Cuenca, Fundación Municipal Turismo Cuenca, s/f: 6) y es una de las locaciones de la Fundación Municipal Bienal de Cuenca ${ }^{2}$. El ingreso es gratuito.

La Reserva y Museo de las Artes Populares - CIDAP (1982) es uno de los servicios del Centro Interamericano de Artesanías y Artes Populares - CIDAP. El inmueble del siglo XX destaca por su fachada de piedra tallada y pulida. Posee siete salas donde se exponen de manera temporal colecciones de artesanía y piezas de arte popular de América. Veinte y seis países se encuentran representados con más de "ocho mil piezas de cerámica, textiles, madera, metales, fibras vegetales, piedra, vidrio, así como utensilios y herramientas de trabajo" (CIDAP, s/f: 2). El museo brinda capacitación artesanal y cuenta con el Centro de Documentación del CIDAP, fundamental para la investigación en el área. El ingreso es gratuito.

El Museo de las Conceptas (1986) funciona en el local del Monasterio de la Inmaculada Concepción, fundado en la ciudad de Cuenca en el año 1599, una de las contadas edificaciones coloniales que conserva la ciudad. En el Monasterio ingresaban las hijas de los conquistadores

1 Año base a partir del cual se continúa monitoreando la llegada de visitantes a los museos.

2 La Bienal Internacional de Pintura de Cuenca se inauguró en el año 1987, a partir de la séptima edición (2001) recibió el nombre de Bienal Internacional de Cuenca. Desde 2008 se constituyó la Fundación Municipal Bienal de Cuenca. 


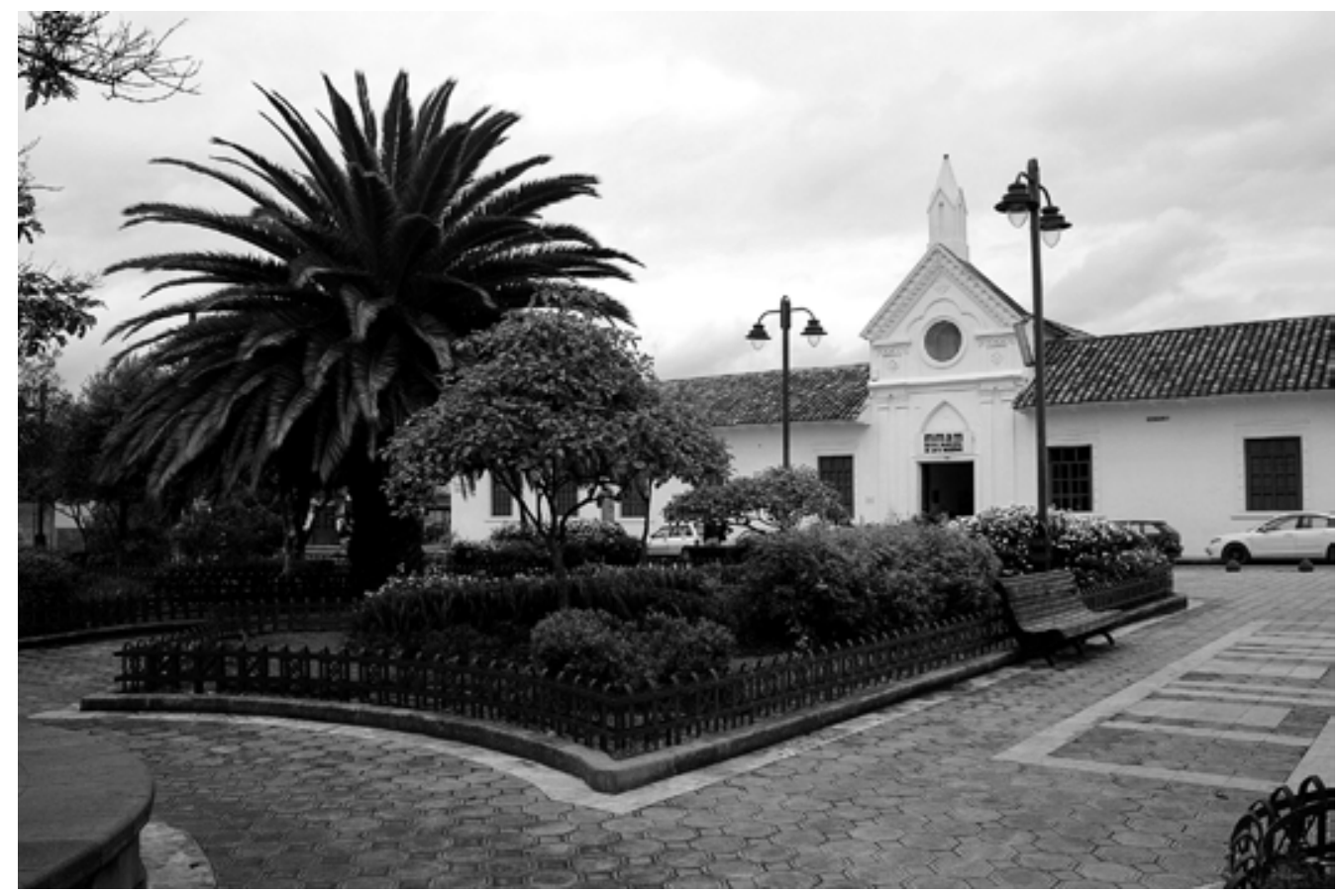

Museo Municipal de Arte Moderno. Foto: Juliana Torres Carrasco.

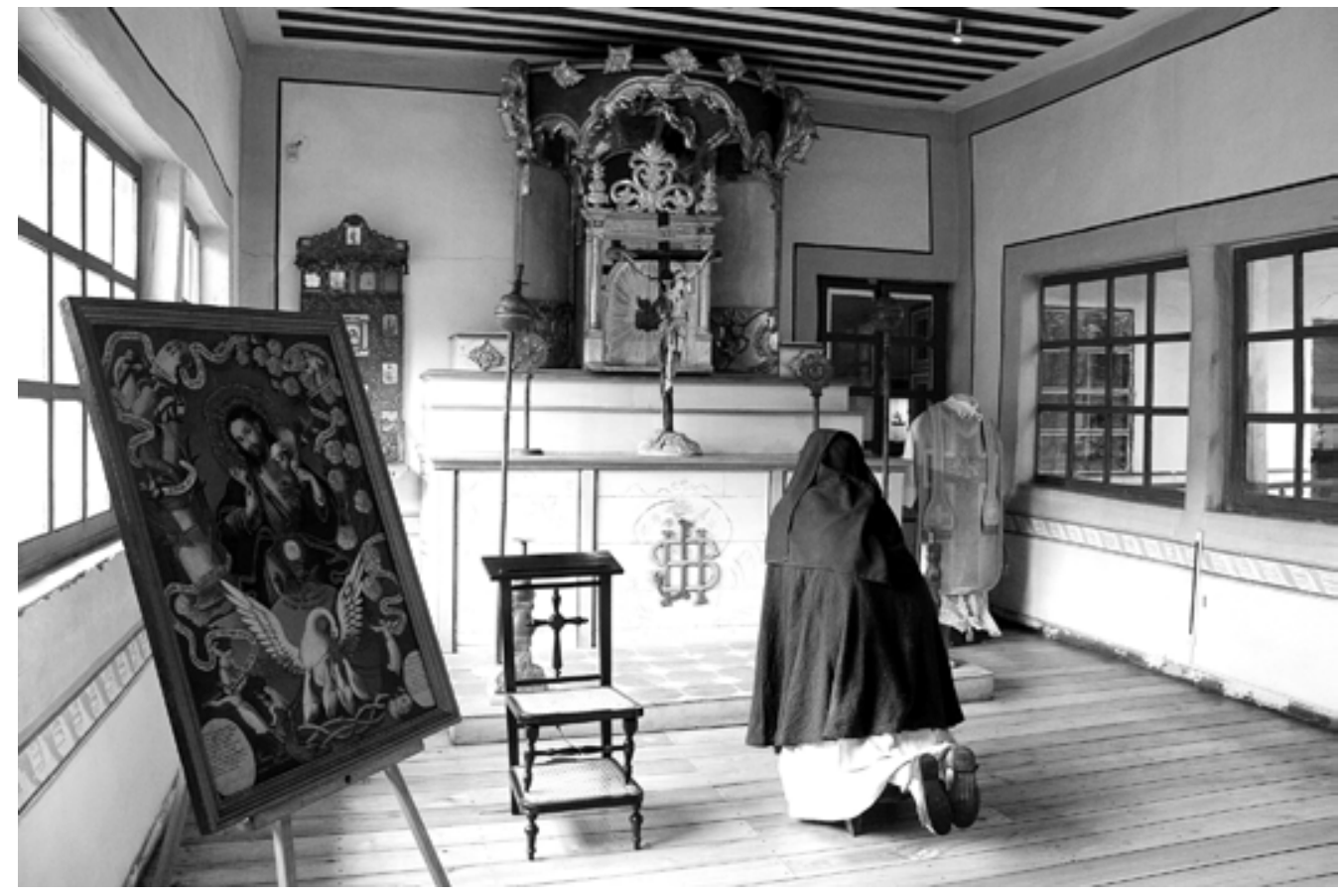

Museo de las Conceptas. Foto: Juliana Torres Carrasco. 
y mujeres de clase alta que optaban por la vida religiosa (Moreno, 2005: 10). Para llegar a ser concepcionistas, las jóvenes debían aportar con una dote. En el transcurso del tiempo la Congregación obtuvo obras de escultura, pintura, muebles, cristalería, joyas y otros bienes que ahora pueden ser apreciados por el público puesto que las religiosas entregaron 470 piezas para la conformación del museo en el año 1986 (Ibíd.: 16). El museo tiene 24 salas permanentes. Los costos para el ingreso difieren de acuerdo al público.

El Museo de las Culturas Aborígenes (1992) es una institución de carácter privado a cargo del Centro Cultural Cordero. La edificación actual se integra a una colonial del siglo XVIII que preserva la fachada exterior. En su interior, quince espacios en orden cronológico y geográfico presentan un recorrido por la arqueología del actual Ecuador mediante variedad de objetos utilitarios, ceremoniales, ornamentales y esculturas, trabajados en distintos materiales como piedra, cerámica, concha, hueso y metal (I. Municipalidad de Cuenca, Fundación Municipal Turismo Cuenca, s/f: 24). El museo incluye una biblioteca de arte, historia, geografía y literatura y un fondo documental que preserva datos, imágenes y documentos de la historia de Cuenca y el Ecuador. La entrada tiene un costo diferenciado de acuerdo al público.

El Museo de la Historia de la Medicina Guillermo Aguilar M. (1992), ocupa el local donde funcionó el Hospital San Vicente de Paúl, construido en el año 1872. Posteriormente por iniciativa de la Sociedad de Historia de la Medicina, capítulo del Azuay, este lugar fue remodelado para museo exponiendo la trayectoria y evolución de la medicina en la ciudad de Cuenca. En catorce salas se exhiben más de 1.200 piezas de diferentes ramas del área de la salud: Odontología, Traumatología, Cirugía, Cardiología, Laboratorio, entre otras. Todos los elementos de la muestra, incluida una botica del primer tercio del siglo XX con su respectivo mobiliario y medicamentos. En la exposición se pueden apreciar "equipos, instrumentos y materiales de la medicina prehispánica, colonial y republicana" (I. Municipalidad de Cuenca, Fundación Municipal Turismo Cuenca, s/f: 14). El ingreso es gratuito.

Museo Magia del Sombrero (2008), se encuentra ubicado en la fábrica de la empresa Homero Ortega dedicada a la producción de Panama Hats, por cinco generaciones. El objetivo del museo es mostrar "la historia del Panama Hat" (Homero Ortega, 2018). El museo expone los diferentes momentos de elaboración del sombrero: tejido, azocado y compostura ${ }^{3}$. Las razones de la demanda del sombrero han variado, de un artículo exclusivo para el trabajo a un accesorio de vestimenta que se exporta a las Américas, Europa, Asia y el Pacífico. El sombrero a más de constituir una forma de ingreso es una tradición familiar que se transmite de generación a generación. En diciembre de 2012 recibió un reconocimiento mundial al ser declarado Patrimonio Inmaterial de la Humanidad, por la UNESCO, lo que incrementa aún más su importancia en general y en el plano cultural en particular. El ingreso al museo es gratuito.

\section{Patrimonio y museos}

El concepto de patrimonio del cual partimos indica que es "una invención y una construcción social" (Prats, 1998: 63). El patrimonio se encuentra atravesado por el poder, entonces ¿qué es patrimonio? La respuesta a esta pregunta está directamente relacionada con agentes sociales y la correspondiente capacidad de negociación y fuerza para sancionar: ¿qué es valioso?, ¿se debe mostrar?, ¿debe perdurar? y ¿se puede musealizar? En este sentido, patrimonio, museo y memoria son objeto de una lucha de poder de los agentes involucrados.

La activación del patrimonio es producto de "los poderes constituidos. El poder político fundamentalmente, los gobiernos locales, regionales, nacionales" (Ibíd.: 68). Aún más, sin poder "no existe el patrimonio" (Ibíd.: 69). A partir de la experiencia histórica, podríamos corroborar las afirmaciones anteriores. Por ejemplo, en Cuenca, pese a ser una ciudad patrimonial, se constata que las instituciones locales en unas ocasiones ejercen su poder y en otras no sobre 


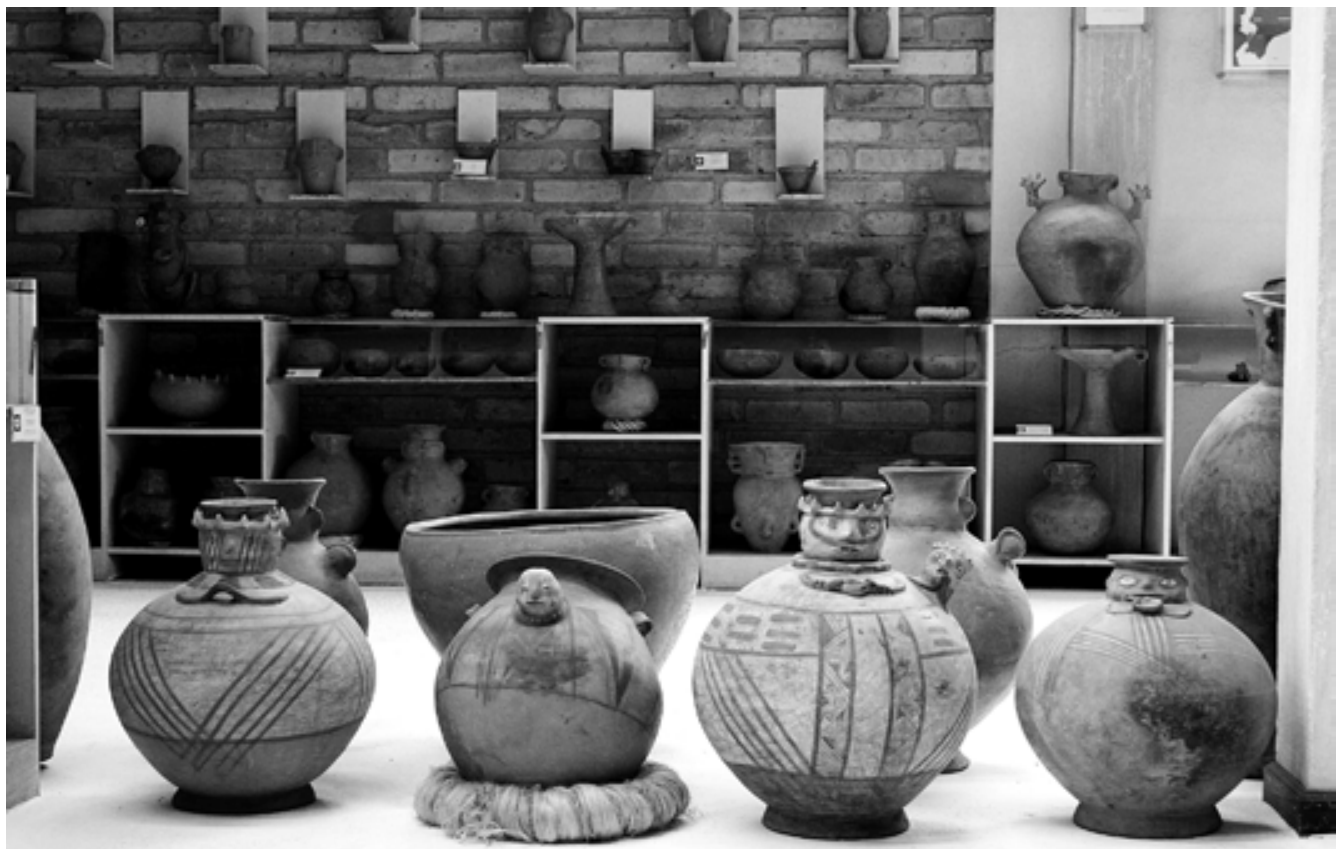

Museo de las Culturas Aborígenes. Foto: Juliana Torres Carrasco.

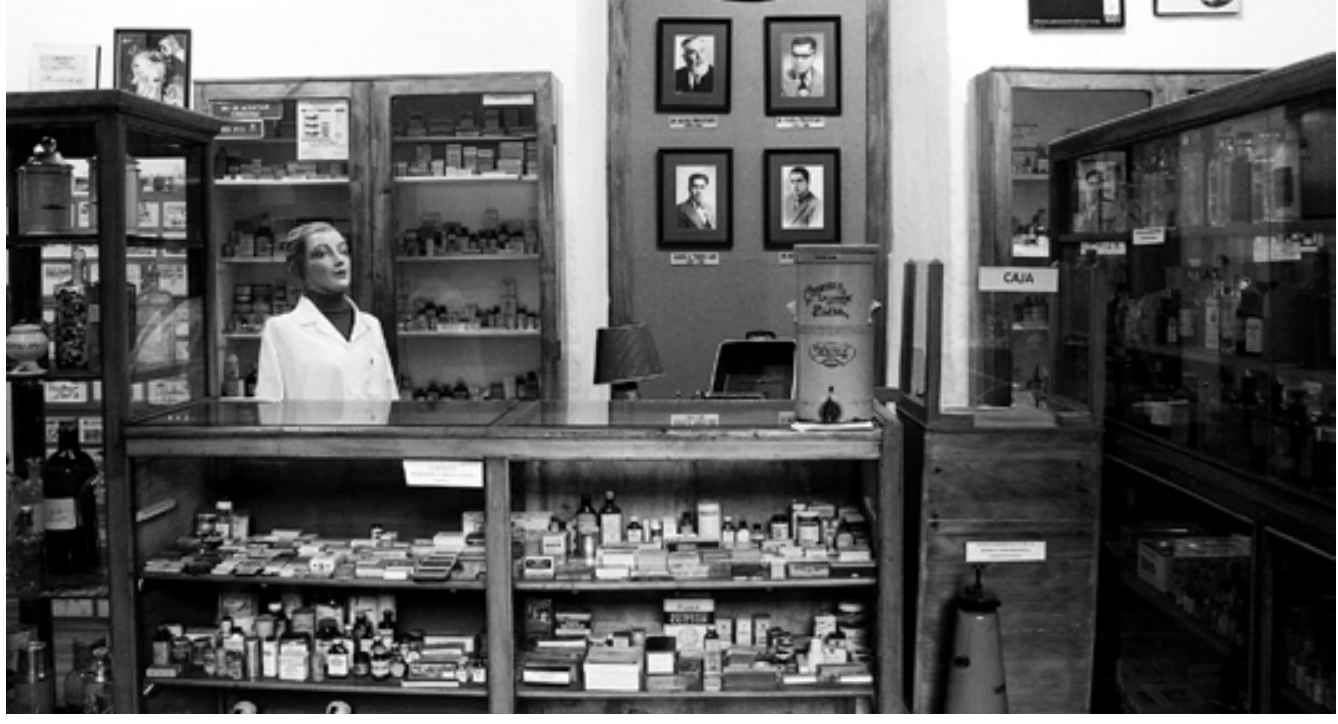

Museo de la Medicina. Foto: Juliana Torres Carrasco. 
el derrocamiento de casas patrimoniales. Por tanto, resulta evidente que intereses de actores económicos logran ser satisfechos en desmedro de la conservación de bienes patrimoniales. La situación continúa a lo largo del tiempo como se puede constatar por los permisos concedidos para erigir construcciones que alteran su entorno.

El patrimonio actual no fue visto siempre de esa forma y tampoco podemos asegurar que lo sea en el futuro, "el patrimonio solo existe ahora y en el ahora" (Criado y Barreiro, 2013: 6). La consideración anterior desacraliza el concepto de patrimonio. Este no es eterno y tampoco tiene una esencia que lo haga especial que lo conduzca a ser reconocido de esta forma por todas las personas. Por el contrario, son estas últimas y las instituciones, en un contexto de ejercicio de poder, las que establecen qué es patrimonio y pueden cambiar de criterio por diferentes circunstancias.

Las activaciones patrimoniales provienen del poder. Lo anterior se constata en el hecho de que en el siglo XIX los museos "respondían a veces muy explícitamente al despertar de un sentimiento nacional y patriótico" (Prats, 1998: 68). En Latinoamérica, durante dicho siglo, la necesidad de construir un pasado común con su correspondiente memoria para afincar una idea homogénea de nación, explica el surgimiento del museo, sobre todo los de carácter nacional. En la ciudad de Cuenca, un ejemplo se encuentra en un caso no considerado en este estudio ${ }^{4}$, la CasaMuseo Remigio Crespo Toral, creada en 1947 con la misión de "...enseñar a las generaciones presentes lo que hicieron de bueno y grande las anteriores" (Albornoz, 1949: 4). Las generaciones anteriores equivalen en este caso a los hombres que se destacaron por su participación política. Por tanto se continuó con el afán decimonónico: constituir una identidad y memoria de la ciudad, desde la visión del grupo social dominante.

García Canclini (1999) ve al patrimonio atravesado por el Estado, el sector privado y los movimientos sociales. La interacción de estos actores explica el uso que se otorga al patrimonio. El autor critica la lógica con la cual éstos tratan el patrimonio. Aboga por un trato que conduzca al equilibrio entre la tradición y los cambios generados por la modernización, todo ello con la participación democrática de los actores involucrados. Valora los procesos antes que los objetos por representar, “...ciertos modos de concebir y vivir el mundo y la vida propios de ciertos grupos sociales" (Girese, 1979 en: Ibíd.: 33). Por tanto, el museo y las políticas patrimoniales "deben tratar los objetos, los edificios y las costumbres de tal modo que, más que exhibirlos hagan inteligibles las relaciones entre ellos, propongan hipótesis sobre lo que significan para quienes hoy los vemos o los evocamos" (Ibíd.).

El museo no constituye el repositorio de objetos muertos y sacros sino un lugar para comprender y explicar la realidad con su mediación. La actividad a favor del patrimonio no debe reducirse a su rescate, hay que considerar su uso social, especialmente la posibilidad de que mediante él, los ciudadanos se apropien de su historia. El museo debe concebirse como un espacio “....abierto e integrador, y como lugar de participación, de generación de conocimiento y creatividad" (Garde, 2013: 197). No obstante, los visitantes identifican el patrimonio con su conservación, aprecian al museo en la medida que conserva la muestra en las mejores condiciones posibles, además de valorar la función del museo como un lugar que permite conocer la historia, destacando otra vez la necesidad de preservarla.

Lo más importante no es el recuerdo, sino el olvido. ¿Qué se debe preservar para la memoria? La respuesta a esta pregunta genera una lucha entre quienes buscan conservar unos recuerdos y aquellos que abogan por mantener otros. Lo narrado en un museo, es producto de una confrontación más o menos evidente a favor de una historia u otra. El mismo episodio puede relatarse silenciando datos. La narración puede presentar solo una parte de los sucesos.

La memoria, el patrimonio y los museos cuentan con actores públicos, privados y sociales quienes con su acción contribuyen a transmitir y preservar una memoria. La "Transmisión, herencias y legados (como cosa dejada a alguien en testamento) suponen la inscripción de sentidos

4 A la fecha de la investigación, la Casa Museo Remigio Crespo Toral se encontraba en proceso de remodelación. 
en un mensaje con la intención de preservación" (Jelin, 2002: 131). El curador contribuye a la memoria o al olvido, determina lo que se presenta o no. Precisamente en este punto se abre la posibilidad para una nueva investigación para responder a la pregunta ¿qué calla el museo?

\section{Patrimonio: historia, memoria y preservación}

La primera impresión que causa a los visitantes la exposición de bienes patrimoniales en los museos estudiados es la sensación de haber contemplado la historia. Esta última concebida como un contacto con los antepasados, con el conocimiento de diversas épocas entre las cuales no encuentran rupturas sino más bien evolución y transición. Obviamente la visión anterior no muestra la realidad histórica. Compartimos el criterio de acuerdo al cual si bien el museo "se erigió como guardián de la memoria de los grupos dominantes (...) su desafío actual consiste en revisar estos supuestos y abrirse a la restitución de historias, identidades y memorias silenciadas" (Cartagena y León, 2014: 80). La comparación entre lo manifestado en los comentarios de los visitantes y el desafío propuesto en la cita muestra la necesidad de arbitrar medidas en los museos para que los primeros adquieran una visión más compleja de la muestra expuesta.

Los visitantes expresan agradecimiento en la medida que los objetos presentados les transportan al pasado. Las muestras sobre dimensiones específicas de la realidad como la historia de la medicina o el sombrero de paja toquilla son apreciadas por el acercamiento que permiten a estas temáticas concretas, y generan sentimientos específicos entre los visitantes. Constatamos que el "...patrimonio es interiorizado de maneras distintas y con distinta intensidad según los individuos" (Espeitx, 2004: 194). En el caso de los turistas extranjeros les resulta particularmente grato identificar elementos de su cultura, expuestos en los museos objeto de este estudio.

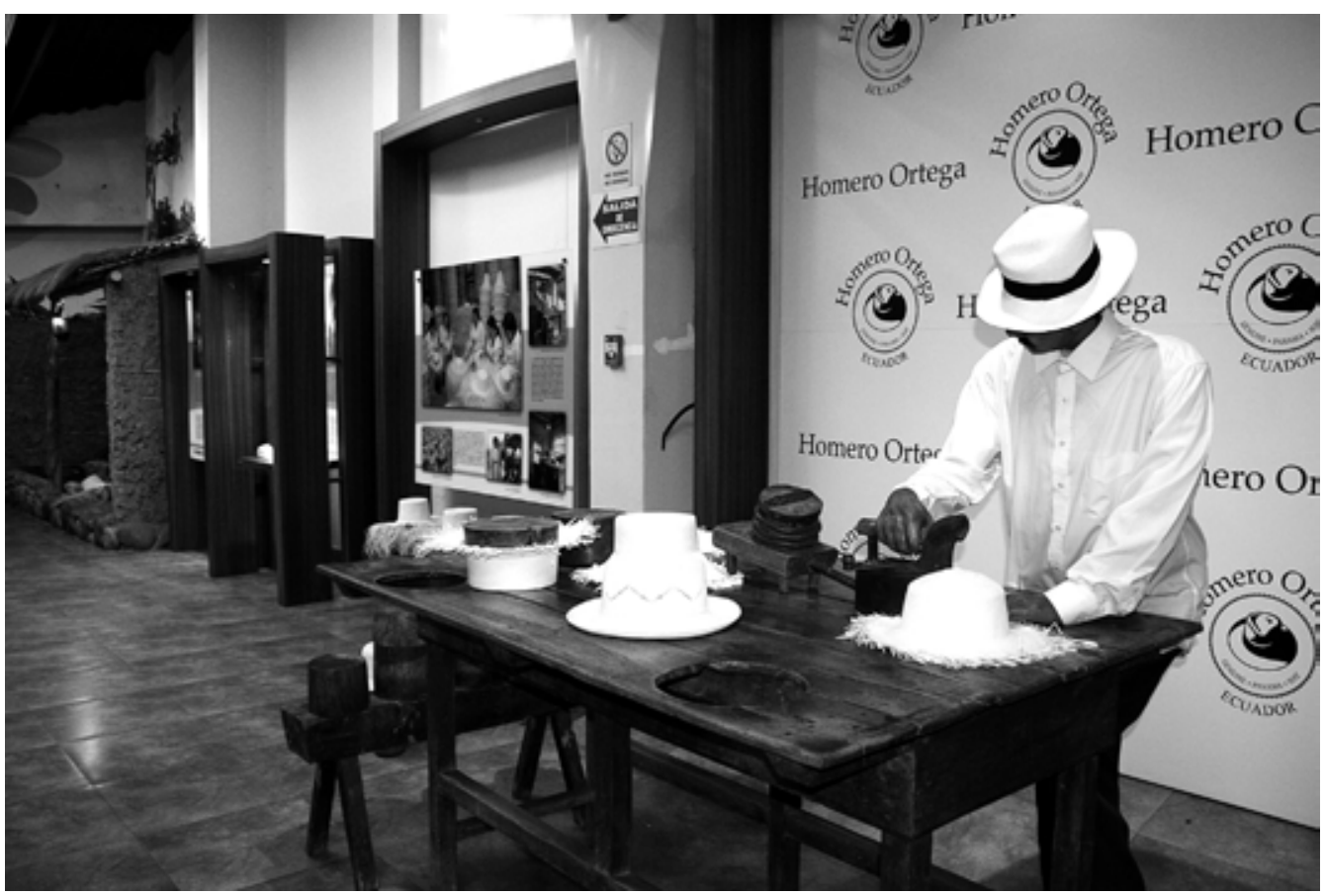

Museo Magia del Sombrero. Foto: Juliana Torres Carrasco. 
Un nuevo acercamiento al patrimonio por parte de los visitantes se da desde la subjetividad. Las reminiscencias experimentadas por los visitantes de los museos son muy personales: constatamos que la muestra conduce a recordar vivencias de la infancia, con matices tan diversos como alegría, tristeza o nostalgia. El museo al hacer presente el pasado contribuye a construir un recuerdo colectivo. Constatamos que la "...memoria tiene entonces un papel altamente significativo, como mecanismo cultural para fortalecer el sentido de pertenencia a grupos o comunidades" (Jelin, 2002: 10-11). En este caso el patrimonio es apreciado en la medida que permite rememorar, y gracias a ello conservar y dar continuidad a aquellos acontecimientos y personajes valorados por los visitantes. Por ejemplo, desde un punto de vista tradicional de la historia, las hazañas de las figuras del movimiento independentista y la de los primeros dirigentes políticos de la inicial época republicana.

Otro aspecto a destacar en los comentarios de los visitantes es su reconocimiento a los museos por la preservación del patrimonio. Identifican la conservación de un bien patrimonial con la continuidad de las tradiciones ligadas a él. Olvidando con ello que no solo se trata de registrar “...objetos 'auténticos' de una sociedad, sino los que son culturalmente representativos" (García Canclini, 1999: 33). Compartimos el criterio de acuerdo al cual frente al patrimonio no basta "una mera actitud defensiva, de simple rescate, sino [contar] con una visión más compleja de cómo la sociedad se apropia de su historia" (Ibíd.). Esta última actitud, de rebasar la preservación y dar paso a una apropiación de la historia, no se llega a apreciar en los comentarios de los visitantes.

Los visitantes manifiestan que la actividad de conservación y protección del patrimonio debe ser indefinida para que las futuras generaciones, puedan conocer los bienes culturales del pasado. En este sentido la muestra es concebida como un testamento, puesto que garantiza para la posteridad reliquias que constituyen la memoria de las generaciones precedentes. Si bien entendemos el sentimiento romántico de rechazo a la finitud, aceptamos que aquello que tiene inicio merece tener fin. Aparte de lo anterior se debe considerar, la afirmación de acuerdo a la cual “...La preservación de los bienes culturales nunca puede ser más importante que la de las personas que los necesitan para vivir" (Ibíd.: 28). Por tanto, a los visitantes les falta advertir la importancia de las personas a la hora de proteger el patrimonio.

La exposición del museo se aprecia por sí misma. Los visitantes expresan opiniones positivas por su valor artístico, importancia histórica, contenido educativo, valor de la colección. La muestra es calificada como singular y trascendente. Por tanto, cumple con la tarea de proporcionar una experiencia estética y cultural de forma adecuada o muy adecuada. Con relación a la atención recibida los visitantes la evalúan como muy buena.

Los edificios que ocupan los museos son apreciados por su valor como sitios de importancia histórica, valor arquitectónico y ejemplo de una lograda restauración. Esto último se constata sobre todo en los comentarios consignados por los visitantes extranjeros.

Los directores destacan el papel de los museos por presentar el patrimonio y lo cual conlleva difundir la historia -entendida como la narración y sucesión de hechos con sus correspondientes protagonistas-, identidad y tradiciones de la ciudad. También resaltan que los turistas extranjeros divulgan en sus países lo apreciado en los museos. Por su parte, los guías de turismo destacan la notable contribución de los museos para la valoración patrimonial de Cuenca.

\section{La gestión del patrimonio en los museos}

Los visitantes de los museos dejaron opiniones favorables sobre la gestión. Las muestras y la exposición son calificadas positivamente, salvo excepciones. De otra parte, hay valoraciones sustentadas en criterios museológicos e incluso sugerencias para la curaduría del museo. El criterio de los visitantes es fundamental, compartimos la afirmación de que el tema del cual se encarga el museo, finalmente es sancionado por su público (Kotler y Kotler, 2001, 2001). 
Los guías turísticos entrevistados observan en la mayoría de museos de la ciudad la ausencia de guianza. Esta carencia es grave, la calidad de la experiencia depende de una guianza actualizada, mejor aún, una mediación profesional, entendida como “...intervenciones llevadas a cabo en el contexto museal, destinadas a establecer puentes entre lo que está expuesto [...] y el significado que dichos objetos y sitios pueden revestir" (Consejo Internacional de Museos, 2010: 47). Por su parte, los directores de los museos resaltan la importancia de la guianza y la mediación, sin embargo la ausencia de profesionales en el área continua irresuelta. En los comentarios de los visitantes se constata que las experiencias insatisfactorias están relacionadas con la falta de un guía.

Visitantes con formación en el área de la museología, señalan falencias museográficas: cédulas únicamente en español, información insuficiente, uso inadecuado del espacio, carencia de indicaciones para apreciar adecuadamente la muestra, mala calidad de la impresión de los textos y de las fotografías. Las respuestas de los museos han sido parciales frente a estas observaciones.

Entre las sugerencias para optimizar el museo están: mejorar las cédulas, la presentación de la información y la museografía considerando la distribución de las salas y la forma de exponer en ellas las colecciones y contar con una buena guianza, -en ningún comentario se ha solicitado mediación-. De acuerdo a los datos obtenidos sobre la nacionalidad de los visitantes de los museos de la ciudad de Cuenca, es necesario que la información esté escrita, aparte del español, en tres idiomas más: inglés, francés y alemán ${ }^{5}$.

Hay un contexto con exigencias antes inadvertidas, por ejemplo, los museos compiten entre sí y por tanto deben atender mejor que otros las necesidades de sus visitantes, superando la oferta de la competencia (Kotler y Kotler, 2001, 2001). En la actualidad los museos deben contar con un público definido. El rol de director es sumamente demandante pues las exigencias de gestión del museo rebasan ampliamente los aspectos museográficos y le instan a obtener recursos para el desarrollo de la institución. Pese a ello, no se han tomado correctivos, posiblemente debido a que los directores de los museos y los guías tienen la percepción de que el criterio de los visitantes, finalmente, es positivo.

De los seis museos considerados para este estudio tres son de carácter público: el Museo Municipal de Arte Moderno (MMAM), el Museo Historia de la Medicina Guillermo Aguilar M. y la Reserva y Museo de las Artes Populares (CIDAP). En el primer caso su financiamiento corre a cargo de la Municipalidad de Cuenca; en el segundo caso, proviene del Ministerio de Salud Pública; y en el tercer caso gracias a fondos fiscales. Es decir, el funcionamiento de estos tres museos se sostiene con base al presupuesto estatal.

El Museo de las Culturas Aborígenes y el Museo Magia del Sombrero son de carácter privado. En el primer caso los visitantes tienen que pagar por su ingreso, rubro importante para su sostenimiento; en el segundo la entrada es gratuita ya que cuenta con el respaldo financiero de la empresa Homero Ortega. Por su parte, el Museo de las Conceptas es administrado por la Fundación Museo de las Conceptas y cuenta con el auspicio de la Municipalidad de Cuenca y la Universidad del Azuay.

El museo contemporáneo demanda una gestión capaz de generar fondos propios a partir de sus recursos en función del desarrollo y crecimiento institucional. Las diferentes actividades que debe cumplir en la actualidad: laboratorio de participación social, talleres, recorridos especializados, proyectos de investigación, exposiciones temporales e itinerantes, conferencias, lanzamiento de libros, exhibiciones de video y cine experimental y la necesidad de introducir nuevos medios y tecnologías requieren de nuevos ingresos para realizarlos adecuadamente (Hernández, 2012).

5 El Registro de Visitas de siete museos de la ciudad de Cuenca, que en el año 2016 recogían esta información, permite establecer que los visitantes extranjeros provenían de 91 países. Las cinco principales naciones de origen fueron: Estados Unidos, 30,36\%; Francia, 12,51\%; España, 7,04\%; Argentina, 7,43\% y Alemania, 6,07\%, que en conjunto sumaron el 63,41\%. Los 86 países restantes representaron el 36,59\%. La información anterior es producto del proyecto "El turismo cultural y los museos en el contexto de la ciudad patrimonial de Cuenca". 
Para lograr lo anotado son necesarias la planificación estratégica y la incorporación de las herramientas de marketing. Los museos tienen que establecer cuáles son sus mercados, si aplican un marketing de masas, de segmentación, de nicho o de segmentos de uno (Kotler y Kotler, 2001). En el caso de los museos en estudio la orientación es de masas pues parten del supuesto de que visitantes nacionales y extranjeros son beneficiarios potenciales sin necesidad de una promoción discriminada. La selección del público objetivo es una tarea que aún no se ha realizado. Los museos no deben continuar dirigiéndose a visitantes en abstracto, por el contrario tienen que establecer su target y dirigirse a él (Cartagena y León, 2014). Hay que trabajar en elementos diferenciadores para los museos pues las dos terceras partes de los directores entrevistados manifiestan que lo distintivo de su institución únicamente tiene que ver con el edificio patrimonial o histórico en el que se encuentran.

La ejecución de alianzas estratégicas entre los museos y otras instituciones es necesaria si consideramos que la mitad de los primeros no tienen convenios con otros entes ya sean públicos, privados, ONG's de carácter nacional o internacional. La otra mitad de museos mantiene relaciones con instituciones locales y tan solo una quinta parte del total ha establecido vínculos con el exterior. Por ello, se deben considerar posibilidades de colaboración interinstitucional para obtener beneficios tangibles e inmediatos. Por ejemplo, el préstamo de piezas para completar colecciones o montar muestras itinerantes, situación que caracteriza el momento actual a nivel mundial.

\section{Conclusiones}

El patrimonio es considerado por los visitantes de los seis museos estudiados como una realidad que debe permanecer inalterable. El museo es percibido como un lugar que congela el patrimonio para garantizar su conservación y posterior exposición para nuevos públicos que se sucedan en el tiempo. Hay un afán de intemporalidad. Ante la oposición cambio-permanencia los visitantes de los museos se pronuncian a favor de la segunda.

Lo que calla el museo pasa inadvertido. Nos preguntamos, ¿los visitantes están dispuestos a conocer historias de abuso, explotación, crueldad durante su tiempo de descanso? Esta pregunta sobre todo para quienes a pesar de tener intereses culturales, ante todo se encuentran en una actividad de ocio.

Los visitantes se impresionan, fundamentalmente, con los rasgos anecdóticos, afectivos y sentimentales de la exposición. Las historias que narran los museos pueden ser muy profundas; sin embargo, la comprensión de la trama política, de los conflictos de poder, de las luchas económicas y sociales que subyacen, pasan inadvertidas. Por ello es necesario lograr mayor profundidad en la apreciación de la muestra mejorando su museografía y mediación.

La experiencia del visitante es enriquecedora si cuenta con una guianza profesional. Sin esta última la observación de la muestra es superficial, sobre todo cuando carece de cédulas que informen en el idioma de los visitantes.

Los museos estudiados no implementan a la fecha herramientas de marketing para su gestión. Particularmente queda la tarea de definir su público objetivo y su consecuente estrategia para captarlo. Un rubro aparte es el de su financiamiento. Sin fuentes propias de ingreso los museos tendrán posibilidades de continuar más no de desarrollarse. 


\section{Bibliografía}

Albornóz, V. 1949, Boletín del Museo Municipal "Remigio Crespo Toral”, 2, Talleres Tipográficos del Consejo Municipal de Cuenca, Ecuador.

Calle Vaquero, M. de la y García Hernández, M. 1998, "Ciudades históricas: patrimonio cultural y recurso turístico", en: Ería, 47, doi:10.17811/er.0.1998.249-280

Canetta, M. 2013, “Olhar sobre o Patrimônio e o Patrimônio Possível”, en: Tecnologia e Ambiente, 19 (1), pp. 4-16, recuperado de: http://periodicos.unesc.net/tecnoambiente/article/download/1317/1265

Chagas, M. y Storino, C. 2014, "Museu, Patrimônioe Cidade”, en: Cuadernos de Sociomuseologia, 3 (47), pp. 7190, recuperado de: http://revistas.ulusofona.pt/index.php/cadernosociomuseologia/article/view/4532/3060

Cartagena, M. F. y León, C. 2014, El Museo desbordado. Debates contemporáneos en torno a la musealidad, Abya -Yala, Quito, Ecuador.

CIDAP. s/f, Reserva y Museo de las Artes Populares, recuperado de: www.cidap.gob.ec

Colle, R. 2011, Análisis de contenido de las comunicaciones. II parte, Colección de Cuadernos Artesanos de Latina/12, Universidad de la Laguna, Universidad de Santiago de Compostela, Revista Latina de Comunicación Social, recuperado de: http://www.revistalatinacs.org/067/cuadernos/12_Colle_interior.pdf

Consejo Internacional de Museos. 2010, Conceptos Claves de Museología, recuperado de: http://icom.museum/ fileadmin/user_upload/pdf/Key_Concepts_of_Museology/Museologie_Espagnol_BD.pdf

Criado-Boado, F. y Barreiro, D. 2013, "El patrimonio era otra cosa", en: Estudios Atacameños. Arqueología y Antropología Sudandinas, N 45, pp. 5-18, recuperado de: http://www.scielo.cl/pdf/eatacam/n45/art02.pdf

Cruz Modino, R. de la 2004, "Patrimonio Natural y Reservas Marinas”, en: Pasos, 2(2), pp. 179-192, recuperado de http://pasosonline.org/Publicados/2204/PS030204.pdf

DeCarli, G. 2007, “Museo y patrimonio local”, en: Moreno L. (Ed.), Tendencias de museología en América Latina. Articulaciones, horizontes, diseminaciones, pp. 209-222, recuperado de: https://issuu.com/ publicacionesdigitalesencrym/docs/sepmal_2015/163

Espeitx, E. 2004, "Patrimonio alimentario y turismo: una relación singular", en: Pasos, 2(2), pp. 193-213, recuperado de: http://pasosonline.org/Publicados/2204/PS040204.pdf

García Canclini, N. 1999, "Los usos sociales del patrimonio cultural”, en: Aguilar Criado, E. (Coord.) Patrimonio Etnológico: Nuevas perspectivas de estudio, Junta de Andalucía, Instituto Andaluz de Patrimonio Histórico, España, pp. 16-33, recuperado de https://dialnet.unirioja.es/servlet/libro?codigo=1525

García Valecillo, Z. 2009, “¿Cómo acercar los bienes patrimoniales a los ciudadanos? Educación Patrimonial, un campo emergente en la gestión del patrimonio cultural", en: PASOS. Revista de Turismo y Patrimonio Cultural, 7, disponible en: http://www.redalyc.org/articulo.oa?id=88111635009

Garde López, V. 2013, “Conocer la experiencia de los visitantes: un paso hacia el museo esencial”, Subdirección General de Museos Estatales, pp. 196-205, recuperado de: https://www.mecd.gob.es/dam/jcr:544c90cf-53794ed8-b5cd-f9eef0789054/03-experiencia-visitantes-def.pdf

Hernández, S. 2012, "La evolución de los museos y su adaptación, en: Cultura y Desarrollo, № 8, recuperado de: http://www.lacult.unesco.org/docc/evolucion_museos.pdf

Homero Ortega. 2018, Museo, recuperado de: http://homeroortega.com/museo/

UNESCO. 2018, Decisión del Comité Intergubernamental: 7.COM 11.12, Intangible Cultural Heritage. Decisions, recuperado de: https://ich.unesco.org/es/Decisiones/7.COM/11.12

Ilustre Municipalidad de Cuenca, Fundación Municipal de Turismo para Cuenca. s/f, Ruta de los Museos, recuperado de: http://cuencaecuador.com.ec/sites/default/files/Folleto\%20Ruta\%20de\%20los\%20museos\%20 Espan\%CC\%83ol.pdf

Ilustre Municipalidad de Cuenca, Junta de Andalucía y Embajada de España. 2007, Cuenca, Guía de Arquitectura, recuperado de: http://www.juntadeandalucia.es/fomentoyvivienda/estaticas/sites/consejeria/ areas/arquitectura/fomento/guias_arquitectura/adjuntos_ga/Cuenca_e.pdf

Jelin, E. 2002, Los trabajos de la memoria, Siglo XXI editores, Madrid, España.

Kotler, N. y Kotler, P. 2001, Estrategia y marketing de museos, Ariel, España, Barcelona.

Moreno, E. 2005, La colección pictórica del Museo de las Conceptas de Cuenca, Escuela de Museología, Universidad del Azuay, Cuenca.

Museo Homero Ortega. s/f, Genuine Panama Hats Cuenca Ecuador, recuperado de http://homeroortega.com/museo/ Prats, L. 1998, "El concepto de patrimonio cultural", Política y Sociedad, 27, pp. 63-76.

Salgado, M. 2004, "Museos y patrimonio: fracturando la estabilidad y la clausura", en: Íconos, N²0, PP. 73-81, Recuperado de: http://www.flacso.org.ec/docs/i20salgado.pdf 